\title{
La experiencia poética como conciencia crítica neorromántica en Octavio Paz
}

\section{The poetic experience as a neoromantic critical awareness in Octavio Paz}

Margarita Gueorguieva Gueorguieva Universidad Michoacana de San Nicolás de Hidalgo

\section{Resumen}

El problema sobre la experiencia poética como conciencia crítica de la realidad moderna, que plantea el pensamiento romántico a la filosofía contemporánea, es hoy tema de interés, entre otras muchas razones, por el efecto que ha causado dicho movimiento al consolidar nuevas visiones que implican como recurso útil la interdisciplinariedad, para una mayor comprensión de los fenómenos, y los conceptos aplicados, para la interpretación de la realidad. La propuesta romántica de repensar la poética (como una posibilidad para reformar la conciencia crítica del hombre contemporáneo) es un tema cuya finalidad gira en torno a configurar los efectos de la influencia que rinde el romanticismo en el pensamiento y la obra del poeta mexicano Octavio Paz.

Palabras clave: romanticismo, conciencia crítica, realidad, experiencia poética, poesía.

\section{Abstract}

The problem on the poetic experience as a critical awareness of modern reality, that raises the romantic thought to contempo- 
rary philosophy, is today a topic of interest, among many other reasons, because of the effect that has caused the movement to consolidate new visions which imply the interdisciplinary nature, as a useful resource to a greater understanding of the phenomena, and the applied concepts, to the interpretation of the reality. The romantic proposal to rethink the poetic experience (as the possibility of reforming the critical consciousness of the contemporary human) it's an issue of which purpose turns around to configure the effects of the influence that the romanticism pays off in the thought and the work of the Mexican poet Octavio Paz.

Keywords: Romanticism, Critical consciousness, Reality, Poetic experience, Poetry.

\section{Introducción}

T a aseveración de Anthony Stanton que dice: "El arco y la lira Les nuestra primera poética romántica” (2015: 23), justifica la importancia de este trabajo. El reconocimiento de Octavio Paz como poeta con fuertes reminiscencias románticas ${ }^{1}$ es un tema que no deja de ser punto de ebullición ante el intento de hallar la correspondencia de su pensamiento con los juicios de los primeros románticos alemanes. La correlación entre uno y otros se asienta, desde mi perspectiva, en la propuesta de otorgarle a la experiencia poética valor epistemológico, un impulso provocado por el interés de buscar formas diferentes para enfrentar la crisis de la realidad

${ }^{1}$ Un importante número de críticos de la obra poética y ensayística de Octavio Paz, entre ellos: Anthony Stanton, Manuel Ulacia, Ramón Xirau, José Antonio Enrico, Mario Santí y Jacques Lafaye, señalan la profunda influencia que tuvieron sobre el poeta mexicano los primeros románticos, sobre todo, los alemanes de la escuela de Jena: conjunto de estudiosos literarios, poetas y filósofos con cede en esta ciudad alemana, a partir de 1796. 
histórica ${ }^{2}$ durante el periodo posmoderno, que operen no sólo en el campo estético sino en otras esferas de la vida. La necesidad de situar el arte y la vida en el mismo plano es una propuesta que se plantea a partir de la segunda mitad del siglo XIX y que ha tenido repercusiones en la estética y la filosofía de los siglos XX y XXI sin dejar de ser tema de discusión tanto en los círculos literarios como filosóficos.

El problema de la experiencia poética como conciencia crítica de la realidad moderna, sugerido por el pensamiento romántico a la filosofía contemporánea, es objeto de interés, entre otras razones, por el efecto que ha causado dicho movimiento al consolidar nuevas visiones que implican como recurso útil la interdisciplinariedad, para una mayor comprensión de los fenómenos, y los conceptos, aplicados en la interpretación de la realidad. La multiplicidad de textos y formas de pensar, manifiestos tanto en los ensayos de Octavio Paz como en la producción de los pensadores románticos, obligarían a abordar un amplio espectro de autores y obras, tanto desde la perspectiva literaria como filosófica e histórica. Sin embargo, las limitaciones de este trabajo merman la posibilidad de profundizar en cada uno de ellos, de modo que tendré que supeditarme a presentar la comparación entre los principios defendidos por Friedrich Schlegel, principal representante del primer movimiento romántico, y los de Paz; del mismo modo, algunas de las diferentes líneas de investigación de la filosofía poética, la estética y la teoría literaria, al mismo tiempo que los análisis realizados por Isaiah Berlin, Paolo D’Ángelo y Rafael Argullol sobre el pensamiento y el arte románticos.

Llevaré a cabo esta tarea en un primer apartado, aproximándome a varias suposiciones sobre las que se fundamenta el roman-

${ }^{2}$ El debate sobre la crisis de la realidad histórica coincide con la aparición del concepto de posmodernidad, (último tercio del siglo XX); cfr. Vattimo (1997) y Compagnon (2010). 
ticismo, para abordar en los siguientes los vínculos que unen las reflexiones románticas con las de Octavio Paz. En un segundo apartado, busco ofrecer un panorama general sobre el saber poético como nueva oportunidad de relacionar los conceptos de verdad y belleza, al mismo tiempo, pretendo establecer una relación entre la visión romántica y la de Octavio Paz acerca de la percepción del arte, no sólo como placer sino como conocimiento. Por último, presentaré la visión, principalmente de Paz, sobre la posibilidad de convertir la experiencia poética en el espacio de unión entre el hombre y el mundo, comparando sus ideas con las propuestas románticas.

\section{La condición trágica del hombre moderno en el pensa- miento romántico}

A lo largo de su historia la palabra "romántico" ha adquirido un sinfín de sentidos; sin embargo, lo primero que viene a la mente es pensar en aquella época que se sitúa en las postrimerías de la modernidad y viene a invertir ciertos parámetros de lo que la creación (el arte) y la teoría (el pensamiento filosófico) occidentales han engendrado durante los siglos anteriores.

A partir de la Revolución Francesa, los cambios históricos y a la vez revolucionarios de fines del siglo XVIII están relacionados con la abolición del sistema feudal y suponen, también, una pérdida de poder por parte de la jerarquía cristiana en la Europa occidental. Desde el punto de vista de Paz, la magia y el misterio fueron reemplazados en este momento por los principios científicos, dando lugar a una vacuidad laica que vino a establecerse en la tierra, conquistando la realidad del hombre e intentando edificar un mundo estable que fuera la patria de todos. En este sentido, afirmará que bajo el nuevo cetro del laicismo la patria deja de ser una comunidad, pues desaparece una gran parte de los valores preservados a lo 
largo de los siglos y el hombre queda huérfano, solitario y desplazado de la naturaleza.

El romanticismo surge en medio de esta atmósfera de desesperación por buscar nuevas formas de expresión y, aunque de carácter efímero, pretendía con ellas manifestar su disconformidad con el mundo y el modo en que los seres humanos se relacionaban con él. Era lógico que fuera así, pues la razón, al proclamarse la única capaz de dar sentido a la vida, en realidad, pretendía la asunción definitiva del poder humano frente al divino, lo que supone un rechazo de lo ilusorio, lo mágico y lo mítico, que dará lugar al vacío y al nihilismo. ${ }^{3}$

El movimiento romántico, según nos dice Rafael Argullol, es una "contundente diagnosis del futuro". La percepción romántica de la desdichada existencia del ser humano en la cultura decimonónica está centrada en la conciencia de "la irresoluble condición trágica del hombre moderno" (Argullol, 2008: 52), la cual, según se ha venido afirmando, es la auténtica raíz de la problemática propia de la mencionada modernidad. Así pues, esta teoría se concreta en una adhesión de los argumentos mitológicos y bíblicos a la literatura, entre los cuales el principal es el lenguaje. En lo que se refiere a la esencia del lenguaje poético, según los románticos, la palabra poética pertenece a otro tiempo, al del origen: base y fundamento de toda la realidad.

En tanto que el ser del hombre es ser en el tiempo, la modernidad ha llegado para destruir la imagen originaria que el hombre tenía del mismo. Claro está que la diferente aprehensión del tiempo a lo largo de los siglos no es la causa fundamental de la ruptura entre lo antiguo y lo moderno, se trata pues de un conflicto entre lo ideal y lo racional que inicia con la Ilustración. Así, la actitud ilustrada asume una postura importante del tiempo: el sentido del

${ }^{3}$ Una excelente referencia sobre esta temática puede ser el libro de Remedios Ávila, Identidad y tragedia, (1999: 21-46 y 50-54). 
concepto se fija en el futuro; de aquí que la historia se llame a sí misma progreso, tal y como afirma Paz. Pero el hecho de que el escritor constata este dato no significa que esté de acuerdo con la postura, más bien como afirma Manuel Ulacia: "la concepción que tiene Paz del tiempo es distinta de las creencias tradicionales modernas. [...] critica la concepción del tiempo lineal y como Eliot busca la experiencia del tiempo original" (1999: 217).

El centro de argumentación, opuesto a la visión ilustrada, se establece en el razonamiento de los románticos a partir de la aceptación del carácter transformador del tiempo como un gran deseo infinito y sucesión de instantes que no pueden detenerse. La enunciación de Isaiah Berlin, acerca de que el mayor precursor del romanticismo Friedrich Schlegel afirma el surgimiento en el hombre "de un deseo terrible e insatisfecho por dirigirse a lo infinito, un anhelo febril por romper los lazos estrechos de la individualidad" (Berlin, 2000: 35), es esencial para entender esta faceta en el pensamiento romántico. En la propuesta artística del romanticismo, la vida humana posee un alto nivel simbólico y, a semejanza de las culturas arcaicas, está impregnada de una fuerza mágica o religiosa que se supone es sagrada porque viene directamente de un dios o un héroe, que ha adquirido su poder gracias al mito.

Es precisamente la angustia por no poder ser como las gloriosas figuras míticas, quienes realizando la identidad entre el hombre y el dios se convierten en seres libres, la que hace exclamar a Hiperión: "el hombre es un dios cuando se entrega a sus sueños, y un pobre ser cuando se pone a reflexionar" (Hölderlin, 2004: 11). El grito de este personaje viene a confesar la enorme decepción de su autor y, en gran medida, de los primeros poetas románticos por la razón universal y los cambios que prometió la Ilustración, tanto en cuestiones de la vida humana como en las prácticas artísticas, en la filosofía, en la moral, en la política. 
Ahora bien, en la poesía griega, por ejemplo, lo predominante es el fundamento mítico de carácter racional, en tanto que intento de dar respuesta a las preguntas irresolubles del hombre; al contrario de lo que sucede en la poesía moderna que se sirve más habitualmente del material histórico, a excepción de la poesía romántica que no excluye el elemento fantástico como forma más antigua y originaria de la creación humana. Por tal razón, Schlegel pretende un "nuevo realismo" que descansará en la armonía de lo ideal y lo real, que "va a anular el curso y las leyes de la razón pensante-razonante y volvernos a poner de nuevo en el bello desorden de la fantasía, en el caos originario de la naturaleza humana" (Schlegel, 1994: 123). A lo anterior, hay que agregarle los nuevos descubrimientos y logros científicos (Schlegel piensa, particularmente, en la Física), y acompañarlos con un razonamiento erudito y "todo se os aparecerá en un nuevo esplendor y en una nueva vida" (Schlegel, 1994: 123). Creo que con esto se concentra el problema en la real o aparente antítesis entre lo ideal y lo racional, que culmina como una polémica contradictoria e irresoluble, por lo menos entre los románticos. Así pues, reviven los conceptos de verdad y belleza en el arte (con una clara base kantiana que se forja precisamente a la luz del racionalismo dieciochesco), y que para los idealistas románticos son términos que presentan la idea unificadora entre conocimiento y moralidad.

Sin embargo, Schiller muestra un resultado opuesto a la visión idealista ya que, según él, no hay un solo ejemplo donde la cultura estética de un pueblo vaya unida a "la libertad política y a la virtud ciudadana, en donde la bondad de las costumbres corra pareja con su belleza, en donde la cortesía del trato se compadezca con la verdad" (Schiller, 1991: 132). Mientras, en la Antigua Grecia, había hombres, como bien apunta Schiller, que no creían el arte un bien y conservaron la distancia intacta entre poesía ("vuelo sublime del espíritu") y verdad ("las leyes, base y cimiento de la sociedad"). Es 
importante recalcar que la polémica iniciada en el seno mismo del romanticismo se ha extinguido en la estética del siglo XX y el concepto de belleza, asociado al arte, cambia radicalmente a partir de las vanguardias; asimismo, la concepción de la verdad se replantea completamente, en tanto que el arte se caracteriza por ser precisamente una mentira.

Si queremos comprender las repercusiones que el romanticismo ha tenido no sólo sobre la estética en nuestra época sino en toda la cultura contemporánea, debemos dejar de pensar de una manera unívoca, buscar otra lógica (diferente de la del principio de la razón) y recordar que no hay un precepto que intente ser la verdad absoluta para explicar la totalidad de lo real, o más bien, como sugiere Octavio Paz, existe otro orden donde "las piedras son plumas y esto es aquello" (Paz, 1972: 99).

El inicio del siglo XX es otro de los periodos históricos con sucesos desastrosos para la humanidad que despierta la conciencia crítica de Octavio Paz. ${ }^{4}$ En este contexto tan desolador, el poeta mexicano busca nuevas formas de expresión para manifestar su postura crítica frente a la injusticia social y a las instituciones gobernantes. Para esto, retoma los conceptos tradicionales del idealismo romántico y dialéctico del siglo XIX, dándoles un enfoque nuevo y una interpretación original. ${ }^{5}$

${ }^{4}$ Rodríguez Ledesma ha descrito minuciosamente el gran impacto de los hechos históricos de la primera mitad del siglo XX sobre el poeta mexicano: Primera Guerra Mundial, Guerra Civil Española, Segunda Guerra Mundial, URSS (persecuciones y campos de concentración contra intelectuales, artistas, comunistas; el pueblo en general), los conflictos ideológico-políticos entre los seguidores de los anarquistas y los comunistas en México y el resto de América Latina, entre otros (vid. Rodríguez Ledesma, 1996).

${ }^{5}$ Después del Segundo Congreso Internacional de Escritores en Defensa de la Cultura, llevado a cabo en 1937 en Valencia, Octavio Paz da un giro a sus ilusiones juveniles sobre el marxismo y el socialismo, considerando que la crítica inicial de las ideologías dominantes, que emprende el marxismo, después de la 
El hombre moderno (entiéndase, contemporáneo especí- ficamente, ubicado en la segunda mitad del siglo XX) es técnico y experto en su profesión debido a que vive la ilusión de las ciencias y el progreso, pero solitario ya que ha invertido los valores y abandonado la poética. Por eso sucede que

No conoce el juego sino el deporte; arroja bombas en Vietnam y envía mensajes a su casa el día de las madres, cree en el amor sentimental y su sadismo se llama higiene, arrasa ciudades y visita al psiquiatra. Sigue atado al cordón umbilical y es explorador del espacio exterior (Paz, 1996: 577).

Todas aquellas son experiencias trágicas para el hombre moderno y, coincidiendo con Remedios Ávila, apuntan hacia la ética y "hablan por sí solas de lo paradójico de nuestro destino y de la finitud de nuestra condición, pero matizan al mismo tiempo el significado de lo ético bajo la sombra de lo trágico" (Ávila, 1999: 128).

De esta manera, se hace comprensible la fascinación del poeta mexicano por los románticos, sobre todo cuando alega que fueron ellos los grandes revolucionarios de la modernidad por haber traído no sólo cambios estéticos, sino por modelar la forma de vivir de los seres humanos, creando así la posibilidad de devolvernos el sentido de nuestra existencia. Al llamarlos "hijos de la Edad Crítica", Paz considera que el rasgo característico de los poetas y pensadores románticos es el cambio, empezando por la negación de la modernidad tal como había sido concebida "por la razón crítica, utópica y revolucionaria. Pero es una negación moderna, quiero decir: una

Revolución Socialista Rusa, se convierte en "teología terrorista" y la vieja clase opresora se sustituye por otra, bajo "la forma del Comité Central" (Paz, 1995: 427). La desconfianza en dicha ideología posteriormente se convierte en escepticismo ante la literatura politizada y comprometida del realismo socialista, cuyas obras debían estar al servicio del Partido Comunista. 
negación dentro de la Modernidad. Sólo la Edad Crítica podía engendrar una negación de tal modo total” (Paz, 1994: 503).

Para Paz, la razón crítica, emblema del nuevo pensamiento que nació con la Revolución Francesa, "renunció a las construcciones grandiosas que la identificaban con el Ser, el Bien y la Verdad" (1994: 502); es decir, los grandes cambios tecnológicos, económicos y políticos muy pronto se convirtieron en los principales responsables de los trastornos en la conciencia humana. En este ambiente el movimiento romántico viene a ser una protesta pasional contra las consecuencias de la Revolución Industrial, asignándole mayor relevancia a los valores tradicionales de integridad y sinceridad en las relaciones interhumanas. Sin embargo, no podemos dejar de constatar el hecho de que los cambios, a partir del siglo XIX, no se hubieran podido realizar sin las condiciones facilitadas por la Ilustración y, de acuerdo con Antoine Compagnon, "una estética de lo nuevo, del reinicio incesante, no parecía concebible antes de que la Revolución francesa le proporcionara un modelo histórico fulminante" (2010: 20).

Ahora bien, de acuerdo con Isaiah Berlin, los románticos no estaban esencialmente interesados en el conocimiento ni en los avances tecnológicos y científicos, "no querían en absoluto ajustarse a la vida, encontrar algún lugar en la sociedad, vivir en paz con su gobierno, o es más, sentir fidelidad por su rey o su república” (2000: 27); más bien, hijos rebeldes de la modernidad, conviven y se funden con ella sólo para destrozarla una y otra vez. De este modo, la re-inventan y la convierten en "una moral, una erótica, una política, una manera de vestirse y una manera de amar, una manera de vivir y de morir" (Paz, 1994: 503).

Por eso, hoy es de vital importancia discutir las ideas sociales, políticas y artísticas; del mismo modo, se hace esencial la necesidad de un cambio de los parámetros lógicos en el arte, no a partir de lo que ha sido o es, sino a partir de lo que deberíamos hacer y lo que 
hemos de ser, es decir, convertir el arte en otra experiencia de la verdad, aunque tendríamos que retomar la propuesta idealista de los primeros románticos. ${ }^{6}$

\section{Saber poético:}

la ignorada intención de unir verdad y belleza

Independientemente del carácter utópico que tiene la proposición romántica de convertir el saber poético en saber verdadero, lo esencial en el arte ya no es sólo el placer que produce, ahora "se opera un acceso al conocimiento, a la realidad, a la verdad misma" (D'Ángelo, 1999: 78), porque la verdad y la belleza van mano a mano. Todo lo que conocemos hasta ahora, como señala Schlegel, nos ha llegado desde "las tinieblas de la Antigüedad" (Schlegel, 1994: 103), mucho antes del canto homérico, dado que nuestro saber del mundo y de los hombres se ha formado a partir del mito y después fue asimilado por los poetas.

De hecho, en sus reflexiones sobre el sentido del uso del mito en la poesía, Schlegel mantiene que la producción poética moderna queda por detrás de la antigua, precisamente porque los modernos no tenemos ninguna mitología. Para él, la antigua mitología era espontánea y se le prestaba de forma natural al poeta, mientras que la moderna se debe crear, por lo que es un producto artificial del ingenio humano.

En ese contexto nace y se desarrolla la poesía moderna, que desde sus inicios muestra discordia con la modernidad al negar el sustento cultural de las tradiciones, que da soporte a toda la civilización occidental. No es difícil caer en la cuenta entonces por qué Octavio Paz insiste en la necesidad de crear nuevas mitolo-

${ }^{6}$ Sin embargo, este planteamiento puede y debe someterse a discusión. La visión de Edgar Allan Poe es un ejemplo muy claro de la insostenible propuesta de reconciliar verdad y poesía (Cf. Poe, 2009). 
gías, las cuales representarán el principio metafórico del lenguaje, mostrando "el otro lado de las cosas, lo maravilloso cotidiano: no la irrealidad, sino la prodigiosa realidad del mundo" (Paz, 1994: 377). Ese lenguaje y las primeras creencias, que no son otra cosa más que imaginación, de las que se ha servido la humanidad son afines a la poesía, que fue el verdadero saber y la verdadera religión de la humanidad. Por otro lado, la imaginación poética también le ha servido a diferentes dogmas para sus fines persuasivos. No obstante, lo que realmente emparenta la poesía y la mística es la misma raíz de la que provienen: el mito (vid. Eliade, 2001: 96-103). Hay que subrayar que, en cuanto a lo religioso se refiere, pienso no en los discursos burocráticos de teólogos y sacerdotes que aportan el mito, sino en las escrituras sacras cuyos hechos fabulosos les son prestados por las antiguas creaciones.

La necesidad de rememorar el pasado heroico, viviente en el mito y a través de él, plantea una posibilidad de acercarse a los otros miembros de la comunidad y revivir con ellos "a la luz de la hoguera los poemas que contaban el origen del mundo y de la etnia” (Paz, 1994: 538) y, en un sentido más estricto, hacer real la comunión. Es evidente la intención de Paz de acercar el hombre al pasado glorioso de sus ancestros y no para buscar la unión con la divinidad, como querían algunos románticos, sino para hacer resucitar a todos los relatos poéticos de grandeza y esplendor de los antiguos héroes, hacer de los vivos y los muertos parte de un todo. Esto es, asociar las propias experiencias con las experiencias de los otros y comprender que la gran mayoría de los seres humanos padecemos los mismos traumas de la modernidad; ${ }^{7}$ es por eso que necesitamos otro trato con nuestros semejantes y con el mundo que nos rodea.

${ }^{7}$ Es interesante la opinión de Marshall Berman en relación con el hombre heroico moderno, la cual se puede revisar en Berman (2013: 141-144). 


\section{La experiencia poética: una posibilidad de unión entre el hombre y el mundo}

El concepto de experiencia poética en Octavio Paz es estudiado, más que sobradamente, ${ }^{8}$ bajo distintas perspectivas, por eso en este trabajo me limitaré sólo a pensar la experiencia poética como la posibilidad de reconciliación entre el hombre y el mundo que, desde mi perspectiva, es la clave de la poética de Paz; al hacerlo, me inclinaré por su propia propuesta en la que apunta que para determinar la poética es menester experimentarla, es decir, "interrogar sus testimonios directos" (1972: 14).

En este sentido, los dos principales componentes poéticos, poesía y poema, son los encargados de interiorizar en la vida propia del poeta, pero su función más importante es la elaboración de las herramientas teóricas del conocimiento poético. En este sentido, es acertada la advertencia de Paz: puede haber actos poéticos que son poesía sin ser poemas, así como hay poemas sin poesía. Y es que la poesía es "el acto mediante el cual el hombre se funda y revela a sí mismo" (1972: 156); por y en la poesía se desvela la condición "verdadera" del hombre, es decir, la poesía es una necesidad creadora que afirma la realidad, una realidad inventada por el poeta, que el lector revive recreándola. Claro, en este sentido es pertinente la aclaración de que no se trata de inventar otra realidad ni de cambiar la realidad vital del hombre, sino de recrear a través de la palabra poética aquello que no es aprehensible de ningún

${ }^{8}$ Los mejores conocedores del pensamiento de Octavio Paz, como Anthony Stanton, Enrico Mario Santí, Hugo J. Verani, Roberto Hozven, Guillermo Sheridan, Manuel Ulacia, entre otros muchos, han señalado reiteradamente diversos aspectos de coincidencia en las reflexiones de Octavio Paz con los postulados románticos: desde vincular la realidad del ser humano con lo sagrado, hasta un trágico modo de interpretación de la realidad existencial. 
otro modo, con el fin de recuperar lo que Paz llama "la mitad perdida del hombre" (78). Los planteamientos que hace Paz, sobre convertir la poesía en instrumento que cambiará al ser humano, se relacionan con la premisa que apuntar que la función de la poesía en la actualidad ha cambiado su rumbo y lo que pretende es divertir, "ya nadie se reconoce en la poesía moderna porque hemos sido mutilados y ya se nos ha olvidado como éramos antes de esta operación quirúrgica” (Paz, 1972: 80).

Respecto de lo dicho, Aguilar Mora afirma que Paz le atribuye a la poesía poderes "sobrevitales", "sobrehumanos" y "sobrenaturales", con lo cual se "vuelve un enérgico reivindicador del romanticismo; pero no de cualquier romanticismo sino del 'otro' romanticismo. Para él ese otro es el de los jóvenes alemanes de Jena” (Aguilar, 2015: 43), pero eso sí, sin concederle a la poesía "una naturaleza trascendente [...]. La poesía es pariente de la religión, pero antes de que ésta se vuelva teología, rito, jerarquía, institución” (42).

Desde mi perspectiva, la experiencia poética en Paz se puede entender en un doble sentido, que está fundado sobre la noción de conocimiento: mística y poesía. Al referirse a la mística, Paz enfatiza que la fuente inspiradora para los grandes inventores antiguos, incluidos los cristianos, ha sido la divinidad pero aun entonces es el poeta el que les da forma a las ideas religiosas, "las transmuta en imágenes y las anima: las cosmogonías y las genealogías son poemas, las escrituras sagradas han sido escritas por los poetas. El poeta es el geógrafo y el historiador del cielo y del infierno" (Paz, 1994: 377).

De forma contraria a la tendencia del pensamiento conceptual, en el conocimiento al que se encaminan la mística y la poesía se reconoce la comunicación enigmática entre el hombre y aquello que lo excede, lo que hace necesaria la manifestación de otra idea, la de lo sagrado. En este caso, lo sagrado está insertado en la vida 
tanto del creyente como del no-creyente y su propósito está direccionado hacia el para qué de las creencias.

Podemos conjeturar que la idea de Paz de vincular la realidad del ser humano con lo sagrado se manifiesta de dos maneras. En primer lugar, se trata de la realidad divina que es una realidad trascendente y se encuentra infinitamente más allá del hombre; para poder llegar a ella los premodernos anhelaban una vida heroica que permitiera el alcance de lo divino y la salvación, una idea muy presente en los primeros poetas románticos, por ejemplo, Hölderlin. En esta experiencia mística "el simbolismo desempeña un papel considerable en la vida religiosa de la humanidad; gracias a los símbolos, el mundo se hace transparente, susceptible de mostrar la trascendencia” (Eliade, 1998: 97). En segundo lugar, la realidad existencial, como parte inmanente del hombre, tiene como objeto de lo sagrado al mismo ser humano, un ser racional y pasional, pero a la vez un ser que experimenta la realidad consigo mismo y con los otros. En este aspecto, lo sagrado para Paz se manifiesta como una realidad diferente del orden religioso y no coincide con la idea romántica. Dicho con Eliade,

A decir verdad, ya no hay 'mundo', sino tan sólo fragmentos de un universo roto, la masa amorfa de de una infinidad de 'lugares' más o menos neutros en los que se mueve el hombre bajo el imperio de las obligaciones de toda existencia integrada en una sociedad industrial (1998: 22).

Contemplando los problemas contemporáneos, tanto del orden ético-moral como estético, Paz busca un nuevo espacio sagrado para los seres humanos, el cual podría convertirse en el sitio de convergencia entre la poesía y la comunión, pensando la poesía en el sentido de valor permanente de la literatura y como intermedio indiscutible entre el pensamiento y la sensibilidad, entre la conciencia y la sinrazón. 
Hay que recordar que para los poetas románticos la línea divisoria entre imaginación poética y revelación religiosa se ha ido borrando; es decir, la imagen poética que es la experiencia de nuestro estado original encierra en sí lo sacro y lo profano, que es la realidad trascendente y originaria de la humanidad. En este sentido, para Paz la poesía fue "verdadera religión y verdadero saber" (1994: 377), independientemente de la excesiva fantasía en el contenido de las escrituras sagradas. Así pues, la poesía es un acto revolucionario "no con, sino frente a las revoluciones del siglo; y su religiosidad es una transgresión de las religiones" (1994: 376). La pretensión romántica de reunir el arte con la vida no es únicamente una aspiración estética sino una forma de vivir y de sentir la realidad, un "acto erótico", dice Paz, y a la vez una política y una visión del mundo. Por ende, la realidad poética no es una realidad abstracta, sino un organismo vivo que se transforma y oscila entre lo mágico y la realidad del presente, entre el espíritu poético y el revolucionario, convirtiendo el antiguo principio religioso en conducto de transmisión hacia la existencia y afirmando la realidad que llena de significado toda la experiencia humana.

Es el poeta, pues, quien convierte la poesía, o mejor dicho, al discurso poético en una forma elevada del pensamiento; de este modo, la energía creadora tiene el fin práctico de transformar el mundo interior y exterior de cada ser humano. Precisamente en esta propuesta subyace un proyecto ideológico y político inscrito en la propia existencia humana. De acuerdo con Juan Carlos Rodríguez, la ambición de una ideología por ser legítima "masivamente y socialmente", no es más que la pretensión de hegemonía en un contexto global, es decir, un proyecto de poder asentado en los valores de la clase dominante. Así, la aspiración que tenían los románticos por convertir el discurso literario en instrumento del cambio social deriva de la estrategia que da privilegio a la interpretación poética de los hechos, la cual le proporciona el carácter tes- 
timonial y veracidad a la crítica practicante, para que ésta se convierta "en un inconsciente admitido y aceptado por todos: como su propia piel, como la verdad misma de la naturaleza” (Rodríguez, 1994: 18). Aun así, aunque la crítica pretendiera una objetividad, no podría escapar de los límites de la "sensibilidad, de la práctica o de la voluntad, los mismos niveles, en fin, en que se movería la Literatura -o el Arte- según todos los planteamientos ilustrados" (Rodríguez, 1994:23). Sin embargo, precisamente por esta razón, la crítica tiende a identificarse con el mismo discurso al que fijaba límites.

Entonces, se puede suponer que, por la posición crítica que asume, el discurso del poeta contemporáneo se convierte en ideológico, en tanto que moviliza el inconsciente del lector. "A veces (sobre todo en 'poesía') tendemos a identificarnos con el autor, a reconocernos en su experiencia" (Rodríguez, 1994: 45). En este proceso, la ideología, el pensamiento y las acciones del poeta se entrelazan con las del lector, lo que nos lleva a la deducción de que la poesía es otra experiencia más y, si es así, indudablemente puede hacer que las cosas cambien, y con ellos las "palabras, sonidos, colores y demás materiales sufran una trasmutación apenas ingresan en el círculo de la poesía” (Paz, 1972: 22). Esto no quiere decir que el lenguaje o las imágenes en el poema dejen de ser medios de significación, sino que trascienden su significado original y se convierten en un producto nuevo, en otra obra, donde se produce el encuentro entre el hombre y la poesía.

Por lo tanto, no es difícil pensar que el nuevo producto, objeto de la poética, es el poema, sólo que no como "artefacto artístico, didáctico o retórico" (Paz, 1972: 14), sino como creación única e irrepetible, que no está sujeta a las normas a las que pretende subordinarla la teoría literaria. El poema es para Paz un universo no susceptible a la interpretación, pues en él gozan de gran libertad las palabras que interrumpen el lenguaje común y nos sitúan "en 
el subsuelo del lenguaje / ahí donde el lenguaje se desdice" (Paz, 2004: 76).

Cabe preguntar, recordando a los románticos, si la aspiración de fundir la teoría con la práctica y el arte con la vida para un fin pragmático es un intento más de enfrentar la realidad vital del hombre concreto o es otra de las imágenes poéticas utilizada para superar las diferencias entre el razonamiento y la imaginación, por un lado, y la poesía y la crítica, por otro.

Para encontrar una respuesta satisfactoria hay que recordar que los primeros románticos alemanes, al intentar abolir las diferencias entre poesía (el arte en general) y crítica (discurso) sobre el arte, convirtieron la poesía en reflexión sobre sí misma; es decir, trataron de mezclar no sólo poesía y prosa, sino también "genialidad", es decir, "literatura creativa -y crítica- o sea, reflexión sobre la literatura. La poesía romántica contiene en sí un momento de reflexión sobre sí misma, es a un tiempo poesía y poesía de la poesía" (D’Ángelo, 1999: 207).

Sobre este punto, es conveniente recordar a Schlegel, más que nada cuando se refiere al concepto trascendental en la poesía y la filosofía. Lo fundamental para él es considerar la manera de acercarse al objeto del conocimiento, lo cual implica la observación y la reflexión sobre el conocimiento mismo. Del mismo modo, la poesía para Paz, debe alzarse en una especie de desdoblamiento, que le permitirá observarse desde afuera y reflexionar sobre sí misma. Esto implica una actitud crítica que incluye no sólo el objeto del conocimiento sino también el sujeto que lo hace posible, de tal suerte, que la poesía se convierte en representación de sí misma en todo aquello que personifica, o sea, ser a un tiempo poesía y poesía de la poesía.

La poesía trascendental es en general un nuevo tipo de poesía, la misma que experimenta Paz al combinar la experiencia científica con la poética, en "unir la conciencia con la inocencia, la 
experiencia y la expresión, el acto y la palabra que lo revela" (Paz, 1965: 133). Esto indica que el poema, aparte de ser una realidad verbal, es un acto en el cual el poeta dice, y en el acto de enunciar, hace. Esto es, sobre todo, un "hacerse a sí mismo: la poesía no sólo es autoconocimiento sino autocreación. El lector, a su vez, repite la experiencia de autocreación del poeta y así la poesía encarna en la historia” (Paz, 1994: 386). A semejanza de esta visión universal de la poética, Ramón Xirau determina que el poema no sólo es un producto humano sino que es "esencialmente transfiguración. Y al transfigurar la experiencia, al llevarnos más allá del lenguaje común, nos permite ahondar en la 'experiencia poética', la cual, a su vez, es la manifestación de nuestra naturaleza original" (Xirau, 2001: 233).

Hay que reiterar que lo dicho sobre la poética no puede persistir excluyendo el lenguaje. Actualmente, una gran parte de los estudios lingüísticos y filosóficos se dedican a buscar el sentido del lenguaje y su uso de forma cotidiana, científica y poética. Por eso, Xirau nos recuerda: "No es que la vida se reduzca a lenguaje; no es que la vida sea lenguaje; más bien lo que sucede es que nos expresamos por medio de un lenguaje cuya misión es fundarnos" (236). No es de extrañar que ésta sea la piedra de toque de la fascinación de Paz por el lenguaje; tan sólo hay que recordar cuando afirma que en el principio está el lenguaje y todo lo que nos rodea no es otra cosa que la recreación que el hombre hace del mundo; es más, el lenguaje es el hombre mismo, ya que estamos hechos de palabras y aquellas forman nuestra única realidad. Paz está convencido de que es imposible comprender la realidad sin el lenguaje, puesto que no hay mundo sin las palabras, porque las palabras aparte de nombrar los objetos, son "la ciencia total del hombre" (Paz, 1972: 131). Esta aseveración me conduce a hacer una reflexión acerca de la construcción hombre / lenguaje como realidad dicotómica. 
Es cierto que el poeta se sirve de otros medios para evidenciar una realidad, imaginativa y reflexiva, que él trata de crear a partir del lenguaje cotidiano es la poética; sin embargo, para crearla es menester destruir la anterior y esto implica una violencia sobre el lenguaje, que el propio Paz había denunciado. Para lograr este objetivo, el primer paso es el desarraigo de las palabras de su uso habitual y el segundo procurar su regreso; así, aquellas se vuelven únicas y al regresar al poema se convierten en objeto de participación, creando otro mundo, a pesar de que siempre parten de un lenguaje ya existente. No puedo dejar de constatar el hecho de que todas estas reflexiones de Paz son influenciadas por el pensamiento romántico, ${ }^{9}$ no obstante, desde los pensadores ilustrados la cuestión del lenguaje simbólico ya está en el centro de las reflexiones filosóficas. Recordemos tan sólo que en el siglo XVIII, el racionalista ilustrado Baumgarten decía que el discurso poético es un discurso sensible, pero "ningún discurso puede considerarse tan científico e intelectual que no sobrevenga, siquiera unido con una representación sensible" (Baumgarten, 1975: 34). Por eso, Paz destaca que el poema se alimenta del lenguaje vivo y común, es decir, de la lengua que se habla, sustentada en la razón y en los sentimientos, y la cual es un producto social, incluso cuando sociedad y poesía se presentan como dos fuerzas antagónicas "según ocurre en nuestra época -y la primera condena al destierro a la segunda, el poema no escapa a la historia: continúa siendo, en su misma soledad, un testimonio histórico" (Paz, 1972: 188).

Para Paz, la creación poética lleva implícita la afirmación de que el poeta, por un lado, siendo miembro de una comunidad mantiene viva la palabra de su pueblo, o sea, la palabra ajena, hija de un

${ }^{9}$ Es emblemática la opinión de Goethe, inspirada por el pensamiento de Hamann (los años 1770), de intentar a colocar el pensamiento metafórico dentro del razonamiento (vid. Berlin, 2000: 69-71). 
lugar y un momento histórico; por otro lado, las imágenes creadas por él constituyen otro lenguaje, anterior a cualquier fecha histórica, es decir, son un comienzo absoluto. La experiencia del poeta es de comunión, en el primer caso, y de soledad, en el segundo. Si su palabra antes ${ }^{10}$ se dirigía al a comunidad, ahora se dirige al individuo concreto, y expresa su rebelión. Paz reflexiona que el poeta moderno no habla el lenguaje de su comunidad ni comparte con ella las mismas ideas y valores. Por tal razón, la poesía es incapaz de evadir la soledad y la rebelión, excepto al cambiar la sociedad y los hombres.

De esta manera, la función de la poesía cambia de rumbo: de una poesía de la sociedad a una poesía para el individuo. La lectura ya no es una manera de unir al pueblo sino un pasatiempo entre las tantas actividades que realiza el hombre. Por eso, para Paz, la experiencia poética es una posibilidad de reconciliación entre los hombres y el mundo. Es decir, no trata de convertir la poesía en el remedio de todos los males humanos, sino que propone un planteamiento diferente para enfrentar la realidad de cada individuo.

Por eso, la realidad del acontecimiento en el poema da paso a la revelación de una realidad personal, la cual ocurre dentro de un tiempo arquetípico que evoca las experiencias de toda una época, de toda una generación y, de este modo, consigue identificar la voz del poeta con la otra voz, la voz del pueblo. La voz del poeta es la que retrata un tiempo y un espacio. Ahí, las experiencias existen para siempre y el acaecimiento estético ya no es un objeto en el espacio y el tiempo sino una acción, un proceso y una experiencia arquetípica.

${ }^{10}$ Cuando digo "antes" me refiero a la utópica idea del tiempo cuando poeta y sociedad (mundo) eran un todo. 


\section{Conclusiones}

En resumen, las propuestas que nos ofrece Octavio Paz para volver a redescubrir las raíces de nuestra humanidad están provocadas por la aceptación, desde el pensamiento contemporáneo, de que la poesía y el arte en general, en los tiempos del gran desarrollo tecnológico y del progreso, son producto inútil y desechable, porque las emociones que muestran y las pasiones que reproducen se resisten a un análisis objetivo que permita construir un concepto del hombre como fundamento y motor de la sociedad. No obstante, en sus reflexiones, Paz da pie a la apertura de un diálogo entre pensar y poetizar, donde la poética aparece como una necesidad de experimentar y decir aquello que es indecible desde el hermetismo del pensamiento occidental posmoderno.

En definitiva, la necesidad de una poética crítica surge en Paz cuando detecta ciertos problemas que según él azotan al pensamiento contemporáneo: la entronización del conocimiento empírico como una referencia absoluta desde el positivismo y la enajenación de las sociedades modernas con el utilitarismo, la cual subordina al individuo a los intereses de la organización económica y política de las clases dominantes.

Las definiciones de Paz sobre el lenguaje poético trascienden los niveles pragmáticos de significación. La palabra poética, a semejanza de la palabra sagrada, es representación y encarnación de nuestros sueños. Por tal razón, en la nueva poesía del siglo XX de la que habla Paz, a partir de visiones y paradigmas racionales, el hombre, gracias a su fuerza de voluntad y el "poder mágico de su espíritu”, puede convertir la realidad de su existencia solitaria en vida colectiva ya sea como un intento de vida armónica con el otro o bien como forma de comunión universal.

Esta ambición implica pensar en una identidad común, que es para Paz la posibilidad de instalarnos en una cultura, compatible 
con otras culturas y civilizaciones. Él da un paso decisivo al comprender que cada sociedad se crea a sí misma pero ninguna puede subsistir al margen de las demás. Por lo tanto, apela tanto a la construcción de una (po)ética en el ámbito de las relaciones interhumanas e interculturales como a vivir una modernidad abierta al reconocimiento y a la valoración de otras culturas.

Debo advertir que las fórmulas inventadas por Octavio Paz para resolver creativamente los conflictos contemporáneos colindan muchas veces con la propuesta utópica, básicamente idealista, de reconstruir el mundo humano. No obstante, la manera de pensar e imaginar problemas concretos y desarrollar posibilidades perceptivas y prácticas para dicha reconstrucción, convierten al intelectual mexicano en modelo para la reflexión actual sobre distintas formas de analizar e interpretar la realidad humana.

\section{Bibliografía}

Ángelo, D', Paolo, 1999, La estética del romanticismo, Juan Díaz de Atauri (trad.), Visor, Madrid.

Aguilar R., José A. (coord.), 2015, Aire en libertad. Octavio Paz y la crítica, Fce/Centro de Investigación y Docencia Económicas, México.

Argullol, Rafael, 2008, El héroe y el único. El espiritu trágico del romanticismo, Acantilado, Barcelona.

Ávila, Remedios, 1999, Identidad y tragedia, Crítica, Barcelona.

Baumgarten, Alexander, 1975, Reflexiones filosóficas acerca de la poesía, José Antonio Miguez (trad., pról., y notas), Aguilar, Buenos Aires.

Berlin, Isaiah, 2000, Las raíces del romanticismo, Conferencias A. W. Mellon en Bellas Artes, 1965, Henry Hardy (ed.), Silvina Marí (trad.), Taurus, Madrid. 
Berman, Marshall, 2013, Todo lo sólido se desvanece en el aire. La experiencia de la modernidad, Andrea Morales Vidal (trad.), Siglo XXI, México.

Compagnon, Antoine, 2010, Las cinco paradojas de la modernidad, Ricardo Ancira (trad.), Siglo XXI, México.

Hölderlin, Friedrich, 2004, Hiperión, Alicia Molina y Rodrigo Rudna (trads.), Coyoacán, México.

Eliade, Mircea, 1998, Lo sagrado y lo profano, Luis Gil Fernández y Ramón Alfonso Diez Aragón (trads.), Paidos, Barcelona.

Paz, Octavio, 1965, Las peras del olmo, UNAM, México.

, 1972, El arco y la lira, FCE, Colección Lengua y Estudios Literarios, México.

, 1994, "Los hijos del limo" y "La otra voz", en La casa de la presencia. Obras completas, t. 1, FCE, México.

, 1996, "Corriente alterna", en Ideas y costumbres II. Usos y simbolos, Obras completas, t. 10, FCE, México.

(2004). "Pasado en claro", en Obra poética II (19691998), FCE, México.

Peralta, Braulio, 1996, El poeta en su tierra. Diálogos con Octavio Paz, Guillermo Sánchez Arreola (ed.), Grijalbo, México.

Poe, Edgar Allan, 2009, Escritos sobre poesía y poética, María Condor (trad.), Hiperión, Madrid.

Rodríguez, Juan Carlos, 1994, La norma literaria, Diputación Provincial de Granada, Granada.

Schiller, Friedrich, 1991, Escritos sobre estética, Juan Manuel Navarro Cordón (ed., y estudio prel.), M. García Morente, M. J. Callejo y J. González Fisac (trads.), Tecnos, Colección Clásicos del Pensamiento, Madrid. 
Schlegel, Friedrich, 1994, Poesía y filosofía, Diego Sánchez Meca (est., prel., y notas), D. Sánchez Meca y A. Rábade Obradó (trads.), Alianza, Madrid.

Stanton, Anthony, 2015, El río reflexivo. Poesía y ensayo en Octavio Paz (1931-1958), El Colegio de México / FCE, México.

Ulacia, Manuel, 1999, El árbol milenario. Un recorrido por la obra de Octavio Paz, Galaxia Gutenberg, Barcelona.

Vattimo, G., 1997, El fin de la modernidad. Nihilismo y hermenéutica en la cultura posmoderna, Alberto L. Bixio (trad.), Gedisa, Barcelona.

Xirau, Ramón, 2001, Entre la poesía y el conocimiento. Antología de ensayos críticos sobre poetas y poesía iberoamericanos, FCE, México.

Recibido: 25 de julio de 2015 Aceptado: 7 de abril de 2016 